\title{
Using a back propagation neutral network based modeling and heuristic algorithms based optimization technique in activated gas tungsten arc welding process
}

\section{Masoud Azadi Moghaddam}

Ferdowsi University of Mashhad

Farhad Kolahan ( $\square$ kolahan@um.ac.ir)

Ferdowsi University of Mashhad

Original Article

Keywords: Activated gas tungsten arc welding (A-GTAW) process, Response surface methodology (RSM), design of experiments (DOE), Back propagation neural network (BPNN), particle swarm optimization (PSO) algorithm, and simulated annealing (SA) algorithm

Posted Date: August 25th, 2021

DOI: https://doi.org/10.21203/rs.3.rs-812301/v1

License: (c) (i) This work is licensed under a Creative Commons Attribution 4.0 International License.

Read Full License 


\section{Abstract}

In this study, a modeling method based on an artificial neural networks model combined with a back propagation algorithm (BPNN) and an optimization procedure based on heuristic algorithms (particle swarm optimization (PSO) and simulated annealing (SA) algorithms) have been proposed for modeling and optimization of activated gas tungsten arc welding (A-GTAW) process in order to tackle the poor penetration drawback occurs during GTAW process. in this study effect of the most important process adjusting variables including welding current (C), welding speed (S)) and percentage of activating fluxes $\left(\mathrm{TiO}_{2}\right.$ and $\left.\mathrm{SiO}_{2}\right)$ combination $(\mathrm{F})$ on the most important quality characteristics (weld bead width (WBW), depth of penetration (DOP), and consequently aspect ratio (ASR)) in welding of AISI316L austenite stainless steel parts have been investigated. Box-behnken and central composite designs (BBD and CCD) based on response surface methodology (RSM) in design of experiments (DOE) method have been employed to gather the required data for modeling and optimization purposes. Then, BPNN has been used to determine the relations between A-GTAW process input variables and output responses. To determine the proper BPNN model architecture (the proper hidden layers' number and their corresponding neurons/nodes in each layer) PSO algorithm has been used. Next, PSO and SA algorithms have been used to optimize the proposed BPNN model in such a way that desired AR, minimum WBW, and maximum DOP achieved. Finally, confirmation experimental tests have been conducted to evaluate the proposed procedure performance. Based on the results, the proposed method is efficient in modeling and optimization (less than 7\% error) of A-GTAW process.

\section{Introduction}

There are different merits (a spatter free process with high weld quality) have been introduced for gas tungsten arc welding (GTAW) process considering of which turned this process for fabricating different alloys including aluminum, magnesium, stainless steel and titanium. However, shallow (poor) penetration has been introduced as a demerit for GTAW process [1 - 3]. To tackle the drawback of poor penetration in GTAW process, different procedures have been introduced. Among the proposed procedures activated GTAW (A-GTAW) is the most important ones. In A-GTAW process a coating of activating fluxes is prepared and applied on the surface of the weldment before the welding process begins $[4,5]$. As the welding process proceeds, the coated layer is melted and vaporized. Due to two phenomena known as arc constriction and reversal of Marangoni convection, depth of penetration (DOP) increases and consequently weld bead width (WBW) decreases. These phenomena have been well documented in refs $[1,2]$.

In GTAW process, when the thickness of specimens exceeds $3 \mathrm{~mm}$, to fill the welding gap a filler metal is required. Whereas, specimens of around $8 \mathrm{~mm}$ could be fabricated in a single welding pass and without even edge preparation in A-GTAW process [6-11]. There is a great deal of studies in which different aspects of A-GTAW process have been taken into account. 
Microstructural and mechanical properties, and corrosion behavior in dissimilar A-GTAW process of AISI316L and P91 steel parts have been investigated by Vidyarthy et al [1]. Ramkumar et al [2], investigated the effect of an activating flux on DOP and mechanical and microstructure properties in GTAW process of titanium alloy (Ti-6Al-4V). An improvement in mechanical and microstructural properties and DOP values in A-GTAW process in comparison to GTAW process have been reported. Zou et al [3], investigated the effect of activating fluxes in GTAW process. Based on this study results, the performance of GTAW process has been enhanced in dissimilar welding of duplex stainless steel and ferrite steel parts. Kulkarni et al [4], investigated the effect of adding activating fluxes on mechanical properties in dissimilar welding of Inconel 800 and Inconel 600. Furthermore, an enhancement for microstructural and mechanical properties in A-GTAW process of P91 weldments have been reported [5, 6]. Kumar et al. [12] investigated the effect of adding activating fluxes in GTAW process. Results of this study illustrated that a full penetration for A-GTAW process reported. Furthermore, the performance of GTAW process could be improved by decreasing WBW and increasing DOP simultaneously using oxidebased activating fluxes. Elimination of edge preparation (required for specimens with more than $3 \mathrm{~mm}$ thickness) and reduction of welding passes for accomplishing fabricating in GTAW process has been reported by Venkatesan et al. [13], using activating fluxes (A-GTAW process). Mechanical properties improvement and distortion reduction were introduced by Chern et al. [14] as the main assets of A-GTAW process. Effect of using different fluxes (including oxide, chloride, and fluoride ones) have been studied by Tathgir et al. [15] in dissimilar welding process of stainless steel and low alloy parts to improve DOP. Based on the research results, using oxide fluxes results in the largest DOP. Whereas, other fluxes had trivial and negligible effect on DOP.

Based on the A-GTAW process literature survey, there are different studies in which the influence of using activating fluxes on different process characteristics (e.g. DOP, WBW, and microstructural and mechanical properties) have been studied. In these papers the lack of modeling and optimization of the process output measures senses. To the best of our knowledge, there is no study in which modeling and optimization of DOP, WBW and AR are considered simultaneously using RSM-based (BBD and CCD) designs of experiments approach, ANN-based modeling, and heuristic algorithms-based (SA and PSO algorithms) optimization technique. As different activating fluxes have different effects on weld bead geometry, mechanical and metallurgical properties of weldments, therefore, in this study the percentage of activating fluxes combination has been considered as the process input variable (apart from welding speed and current) and optimized in such a way that DOP increases, WBW decreases and proper value for AR achieved simultaneously. In this study based on the preliminary experimental tests carried out using DOE (screening) approach and literature survey studied, three inputs parameters (welding current (I), welding speed (S) and percentage of activating fluxes combination (F)) have been taken into account as adjusting parameters and their corresponding intervals and levels determined. According to the number of input variables and their predetermined levels, the most appropriate design matrix (CCD and BBD based on RSM) have been considered. Next, to determine the relationships between process input variables and output characteristics, back propagation neural network (BPNN) has been used. Next, PSO algorithm has been used to find the best BPNN architecture (number of hidden layers and nodes/neurons 
in each layer). Finally, the optimal values of process input variables for multi-response optimization have been determined using PSO algorithm. The SA algorithm has also been used to check the adequacy of PSO algorithm and avoid getting trapped in local minima. The proposed approach has been carried out on AISI316L austenitic stainless steel parts. Based on the achieved results, an optimized formula $\left(\mathrm{TiO}_{2}+\right.$ $\mathrm{SiO}_{2}$ ) has been proposed in such a way a desired ASR with minimum WBW and maximum DOP achieved.

\section{Experimental Set Up}

\subsection{Equipment and material used}

To carry out the experimental tests based on the CCD and BBD design matrixes proposed by RSM, a DIGITIG 250 AC/DC welding machine has been employed (Fig. 1). Furthermore, in this study, Argon (with $99.7 \%$ purity) has been used as the shielding inert gas.

AISI316L stainless steel sheets with dimension of $100 \mathrm{~mm} \times 50 \mathrm{~mm} \times 5 \mathrm{~mm}$ have been considered as specimens (Fig. 1). In this study, a combination of Nano oxide fluxes $\left(\mathrm{TiO}_{2}, \mathrm{SiO}_{2}\right)(+99 \%, 20-30 \mathrm{~nm}$, amorphous) have been used as activating fluxes. Firstly, to assure the powder particle size, FESEM test has been employed (Fig. 2). Figure 3 represents the FESEM results of the oxide-based activating fluxes used which confirmed the Nano-scale claimed by provider. Next, a paste like coating of fluxes prepared by adding a mixture of fluxes (20-grams of $\mathrm{TiO}_{2}$ and $\mathrm{SiO}_{2}$ ) with $20 \mathrm{ml}$ of methanol (as a carrier solvent) using approximately 20 minutes of mechanical, magnetic and ultrasonic mixers (Fig. 4)) [1, 2]. Then, the paste like flux has been applied on the surface of the specimen with a brush and dried before the welding process begins (Fig. 5).

\subsection{Response surface methodology (RSM)}

Defining a proper experimental design matrix using of which experiments required for modeling and optimization purposes are conducted, is the next step after selecting the main process input variables and their corresponding intervals and levels. In this study, the main process variables and their corresponding intervals and levels have been determined based on the literature survey and preliminary experimental tests using screening procedure. Generally, to facilitate the identification of each individual process variables influences, establish the relations between process input variables and output measures, and determine the optimal levels of input variables in order to get the desired responses (in this study, minimum WBW, maximum DOP, and desired ASR), DOE approach is employed.

There are different approaches in DOE method, among which response surface methodology (RSM) acts as a powerful tool. RSM comprises different designs, including central composite design (CCD) (spherical CCD, rotatable CCD, and etc.), box-behnken design (BBD), and hybrid designs (Fig. 6) [20].

\subsection{Determination of adjusting variables and their corresponding intervals and levels}


There are different variables affecting the A-GTAW process among which, the most influential ones based on the literature review and screening method used are welding speed (S) and welding current (I). Furthermore, percentage of activating fluxes combination $(F)$ has been considered as a process input variable to achieve the merits of both in this regard [1-3]. Similarly, process quality characteristics including DOP, WBW, and ASR are the most important responses of A-GTAW process. To determine the possible working intervals of each process input variables, welding references studied and some preliminary tests have been carried out [8-15]. The process input variables and their possible intervals and levels have been shown in Tables 1,2 considered for CCD and BBD designs respectively. Other input variables with trivial effects have been considered at an optimum fixed level. In this study, a CCD's $L_{20}$ and a BBD's $L_{17}$ matrix have been opted (Tables 3 and 4).

Table 1

Process input variables and their corresponding intervals and levels considered for CCD

\begin{tabular}{|llll|}
\hline Process parameter & Flux combinations $\left(\mathrm{SiO}_{2}-\mathrm{TiO}_{2}\right)$ & Welding current & Welding speed \\
\hline Symbol & $\mathrm{F}$ & $\mathrm{C}$ & $\mathrm{S}$ \\
\hline Unit & $\%$ & Amps & $\mathrm{mm} / \mathrm{sec}$ \\
\hline Interval & $0-100$ & $90-130$ & $110-190$ \\
\hline Level 1 & $0-100$ & 90 & 110 \\
\hline Level 2 & $25-75$ & 100 & 130 \\
\hline Level 3 & $50-50$ & 110 & 150 \\
\hline Level 4 & $75-25$ & 120 & 170 \\
\hline Level 5 & $100-0$ & 130 & 190 \\
\hline
\end{tabular}

Table 2

Process input variables and their corresponding intervals and levels considered for BBD

\begin{tabular}{|llll|}
\hline Process parameter & Flux combinations $\left(\mathrm{SiO}_{2}-\mathrm{TiO}_{2}\right)$ & Welding current & Welding speed \\
\hline Symbol & $\mathrm{F}$ & $\mathrm{C}$ & $\mathrm{S}$ \\
\hline Unit & $\%$ & Amps & $\mathrm{mm} / \mathrm{sec}$ \\
\hline Interval & $25-75$ & $100-120$ & $125-175$ \\
\hline Level 1 & 25 & 100 & 125 \\
\hline Level 2 & 50 & 110 & 150 \\
\hline Level 3 & 75 & 120 & 175 \\
\hline
\end{tabular}

\subsection{Experimental results}


A random order in conducting experiments has been used to increase the accuracy of the experiments. After welding, three types of responses (DOP, WBW, and ASR) have been measured from each specimen (Tables 3 and 4).

Two cross sections on each sample have been made in order to measure DOP, WBW, and consequently ASR. Next, to clearly show DOP and WBW, the cut faces have been polished smoothly and etched (Figs. 7). Then, for taking images an optical microscope has been used (Fig. 7). To determine samples' DOP and WBW, images have been processed by MIP software (Fig. 7). Results of the measuring process has been illustrated in Figs. 8 and 9. 
Table 3

Experimental conditions based on CCD and their corresponding measured outputs

\begin{tabular}{|c|c|c|c|c|c|c|}
\hline No. & $\begin{array}{l}\text { Welding } \\
\text { speed } \\
(\mathrm{mm} / \mathrm{sec})\end{array}$ & $\begin{array}{l}\text { Welding } \\
\text { current } \\
\text { (Amp) }\end{array}$ & $\begin{array}{l}\text { Flux } \\
\text { combination } \\
\left(\mathrm{SiO}_{2}-\mathrm{TiO}_{2}\right)\end{array}$ & $\begin{array}{l}\text { Depth of } \\
\text { penetration }(\mathrm{mm})\end{array}$ & $\begin{array}{l}\text { Weld bead } \\
\text { width } \\
(\mathrm{mm})\end{array}$ & $\begin{array}{l}\text { Aspect ratio } \\
\text { (AR) }\end{array}$ \\
\hline 1 & 130 & 120 & 25 & 5.755 & 7.693 & 1.337 \\
\hline 2 & 150 & 110 & 50 & 5.041 & 7.905 & 1.568 \\
\hline 3 & 170 & 100 & 75 & 5.367 & 7.224 & 1.346 \\
\hline 4 & 170 & 100 & 25 & 3.142 & 9.466 & 3.013 \\
\hline 5 & 150 & 110 & 50 & 4.711 & 7.617 & 1.617 \\
\hline 6 & 150 & 130 & 50 & 6.827 & 7.703 & 1.128 \\
\hline 7 & 170 & 120 & 25 & 3.92 & 8.425 & 2.149 \\
\hline 8 & 170 & 120 & 75 & 5.524 & 5.923 & 1.072 \\
\hline 9 & 130 & 100 & 25 & 4.873 & 8.125 & 1.667 \\
\hline 10 & 150 & 110 & 50 & 4.321 & 7.92 & 1.833 \\
\hline 11 & 150 & 110 & 50 & 4.85 & 7.51 & 1.548 \\
\hline 12 & 130 & 100 & 75 & 6.356 & 6.676 & 1.051 \\
\hline 13 & 150 & 110 & 50 & 4.95 & 7.847 & 1.585 \\
\hline 14 & 150 & 110 & 100 & 6.124 & 5.604 & 0.915 \\
\hline 15 & 110 & 110 & 50 & 6.254 & 6.393 & 1.022 \\
\hline 16 & 150 & 90 & 50 & 4.61 & 7.778 & 1.687 \\
\hline 17 & 150 & 110 & 50 & 4.906 & 7.803 & 1.591 \\
\hline 18 & 130 & 120 & 75 & 7.894 & 6.91 & 0.875 \\
\hline 19 & 150 & 110 & 0 & 3.133 & 9.985 & 3.187 \\
\hline 20 & 190 & 110 & 50 & 3.85 & 7.46 & 1.938 \\
\hline
\end{tabular}

To relate the process input variables and output responses for CCD and BBD matrixes, regression equations proposed for DOP, WBW, and ASR (Equations 1-6).

$\mathrm{DOP}=24.19+0.03358 \times \mathrm{F}-0.381 \times \mathrm{C}+0.000230 \times(\mathrm{S} \times \mathrm{S})-0.000960 \times(\mathrm{S} \times \mathrm{C})+0.002608 \times(\mathrm{C} \times \mathrm{C})(1)$

WBW $=-28.83+0.0549 \times F+0.3483 \times S+0.1842 \times C-0.000628 \times(F \times S)-0.000526 \times(S \times S)-0.001340 \times(S \times C)$ (2) 
$W / D=-15.39+0.1125 \times S+0.1634 \times C+0.000155 \times(F \times F)-0.000448 \times(F \times S)+0.000280 \times(F \times C)-$ $0.000109 \times(\mathrm{S} \times \mathrm{S})-0.000395 \times(\mathrm{S} \times \mathrm{C})-0.000615 \times(\mathrm{C} \times \mathrm{C})(3)$

$\mathrm{DOP}=-21.9+0.1187 \times \mathrm{F}+0.425 \times \mathrm{C}-0.001189 \times(\mathrm{F} \times \mathrm{F})-0.000189 \times(\mathrm{F} \times \mathrm{S})+0.000435 \times(\mathrm{F} \times \mathrm{C})+0.000251 \times$ $(\mathrm{S} \times \mathrm{S})-0.000879 \times(\mathrm{S} \times \mathrm{C})-0.001251 \times(\mathrm{C} \times \mathrm{C})(4)$

WBW $=-97.8-0.1743 \times F+0.4264 \times S+1.338 \times C+0.000561 \times(F \times S)+0.000761 \times(F \times C)-0.001564 \times(S \times S)$

$+0.000381 \times(\mathrm{S} \times \mathrm{C})-0.00630 \times(\mathrm{C} \times \mathrm{C})(5)$

$A S R=e^{-6.60} \times F^{-0.2853} \times S^{2.005} \times C^{-0.392}(6)$

Table 4

Experimental conditions based on BBD and their corresponding measured outputs

\begin{tabular}{|c|c|c|c|c|c|c|}
\hline No. & $\begin{array}{l}\text { Welding } \\
\text { speed } \\
(\mathrm{mm} / \mathrm{sec})\end{array}$ & $\begin{array}{l}\text { Welding } \\
\text { current } \\
\text { (I) }\end{array}$ & $\begin{array}{l}\text { Flux } \\
\text { combination } \\
\left(\mathrm{SiO}_{2}-\mathrm{TiO}_{2}\right)\end{array}$ & $\begin{array}{l}\text { Depth of } \\
\text { penetration }(\mathrm{mm})\end{array}$ & $\begin{array}{l}\text { Weld bead } \\
\text { width } \\
(\mathrm{mm})\end{array}$ & $\begin{array}{l}\text { Aspect ratio } \\
\text { (ASR) }\end{array}$ \\
\hline 1 & 50 & 175 & 100 & 3.96 & 6.21 & 1.57 \\
\hline 2 & 50 & 150 & 110 & 4.65 & 7.66 & 1.65 \\
\hline 3 & 50 & 150 & 110 & 5.10 & 7.58 & 1.48 \\
\hline 4 & 50 & 125 & 120 & 6.16 & 6.12 & 0.99 \\
\hline 5 & 50 & 125 & 100 & 4.84 & 5.07 & 1.05 \\
\hline 6 & 75 & 125 & 110 & 5.65 & 5.74 & 1.02 \\
\hline 7 & 50 & 150 & 110 & 4.79 & 8.26 & 1.72 \\
\hline 8 & 75 & 150 & 120 & 4.95 & 7.62 & 1.54 \\
\hline 9 & 50 & 175 & 120 & 4.42 & 7.64 & 1.73 \\
\hline 10 & 50 & 150 & 110 & 4.83 & 7.91 & 1.64 \\
\hline 11 & 25 & 125 & 110 & 4.58 & 6.75 & 1.47 \\
\hline 12 & 75 & 175 & 110 & 3.64 & 7.82 & 2.15 \\
\hline 13 & 25 & 175 & 110 & 3.04 & 7.44 & 2.44 \\
\hline 14 & 75 & 150 & 100 & 4.03 & 6.61 & 1.64 \\
\hline 15 & 50 & 150 & 110 & 4.68 & 7.96 & 1.70 \\
\hline 16 & 25 & 150 & 120 & 3.63 & 7.57 & 2.08 \\
\hline 17 & 25 & 150 & 100 & 3.15 & 7.33 & 2.32 \\
\hline
\end{tabular}




\section{Back Propagation Neural Network (Bpnn)}

In order to relate a set of input-output parameters in a system (a manufacturing process such ) different procedures are being employed among which ANNs are the most extensively used ones. ANNs are embrace of a set of connecting processing units named neurons/nodes, organized in each layer (input, hidden and output). An illustration of a perceptron is shown in Fig. 9 (a), where each input variable (defined as $x_{i}$ ) is related with a weight $\left(w_{i}\right)$ which indicates a portion of the input variable to the neuron for processing. Furthermore, $b$ is the bias and $y$ the output signal.

Fig 9 (a), represents a linear perceptron's inputs $\left(x_{1}-x_{n}\right)$ combination. Next, a signal $\left(v=\sum_{i=1}^{N} x i \times w i+b\right)$ is obtained and transferred using function $(f)$ in order to obtain the output signal $(y)[17,18]$.

Different structures for ANN have been proposed among which multi-layer perceptron (MLP) has been extensively used due to its ability to solve different problems (including non-linear separable/continuous). MLP networks embraces an input layer, hidden layer/s (one or more), and an output layer (Figure 9 (b)). In the training stage, a supervised way is used to determine the biases and weights, based a set of inputoutput data pairs, which allows the MLP to learn the input-output parameters relations (in this study, process input variables and output responses). In BPNN, an algorithm (back propagation) is employed in which error of each MLP's input-output pair is calculated and then propagated from the last (output) layer to the first (input) layer, adjusting the biases and weights of the MLP network to the error devoted by its neuron proportionally, is used [15]. The details in this regard are well documented in Refs. [16, 19].

Commonly, the architecture of ANN models is determined based on trial and error. Whereas, in this study in order to eradicate this error, PSO algorithm has been used to determine the proper BPNN's architecture. The hidden layers' number was varied from 1 to 3 ; hence a $\mathbf{3}$ (number of process input variables) $-n_{1}-$ $\mathrm{n}_{2}-\mathrm{n}_{3}-\mathbf{3}$ (number of process output characteristics) structure was constructed; where the number of neurons/ nodes for the 1 st to 3 rd hidden layers are $n_{1}, n_{2}$, and $n_{3}$ respectively. The training stage acts as a way to find the proper weights and architecture of net that leads to minimum error between the desired (or predetermined) and predicted measures.

The comparison between process responses and the proposed model based on CCD matrix prediction has been shown in Fig. 10. Fig.11 shows the variation of mean squared error (MSE) during the training process of BPNN model. The performance of the proposed model has been illustrated in Fig.12.

\section{Problem Definition}

Obtaining the best set of A-GTAW process variables to simultaneously maximize DOP, minimize WBW and attain desired ASR, is the main objective of this study. Consequently, process output measures could be considered together to build a multiple process response in the optimization procedure. Thus, the optimal design could be formulated as a multi-response optimization problem illustrated as Eq. (7): 
Maximum DOP $=$ DOP $(F, I, S)(7)$

Minimum WBW $=-$ WBW $(F, I, S)$

Desired AS $=[1-1.4]$

In this study achieving low WBW, high DOP and desired AR simultaneously required for multi-criteria optimization. Therefore, process multi-responses are changed into a single measure using Eq. (8), where $w_{1}$ and $w_{2}$ are weighting coefficients to show the importance of DOP and WBW respectively. Based on the literature survey which has been confirmed via experimental tests, in order to avoid solidification cracks the best interval for AR is [1.0-1.4] [20]. Solidification cracking tendency is significantly influenced by width to depth ratio (WBW to DOP (W/D), which can be minimized by ensuring that this ratio is between 1 and 1.4. (Fig. 13).

Minimize $F(F, C, S)=\left(W_{1} \times D O P\right)-\left(W_{2} \times W B W\right),(1.0<A R<1.4)(8)$

\section{An Introduction To Heuristic Algorithms}

Nowadays different heuristic algorithms for different optimization purposes have been proposed (including simulated annealing (SA), genetic (GA), Tabu search (TS), ant colony (AC), bee colony (BC), particle swarm optimization (PSO), and etc.), among them PSO and SA, due to their advantages are mostly being employed. Easy programming (few input parameters to adjust) and fast convergence are the major merits of PSO algorithm. Whereas, in high dimensional space, falling into local optimum traps may be considered as a weakness for PSO algorithm. Based on the SA mechanism this algorithm could avoid getting trapped into local optimum which can be considered as a major excellence over other algorithms [19].

In this study, PSO and SA algorithms due to their mentioned merits, have been employed as the heuristic algorithms to optimize A-GTAW process variables in order to achieve maximum DOP, minimum WBW and proper value of ASR. In this study, PSO has been used twice (to determine the most appropriate architecture for BPNN and optimize the process measures). Next, SA algorithm has been used to evaluate the performance of PSO algorithm. Furthermore, a set of validation experiments has been conducted in order to confirm the proposed approach.

\subsection{Simulated annealing algorithm}

To interpolate between the process input variables intervals to select the most appropriate values of process input parameters reaching the desired output characteristics (e.g. minimum WBW and maximum DOP), different procedures have been introduced among which heuristic algorithms have been extensively employed for different optimization problems. All heuristic algorithms are reminiscent of biological or physical processes. In this regard, SA algorithm is reminiscent of annealing in heat treatment process [21, 22]. In annealing process, metals are heated up to a specific and pre-determined 
temperature (near the melting point), at which all metal particles are in random motion. Then, all metal particles rearranged by cooling down slowly toward the lowest energy state. As the cooling process is conducted appropriately slowly, lower and lower energy states are achieved until the lowest energy state is reached. Similarly, in A-TIG welding process the lowest energy level gives the optimized value for variables based on an energy function is created and minimized. The mechanism of SA algorithm is defined as follows [23]:

Defining an acceptable answer space and generating an initial random solution in this space. Next, the new solution's objective function $\left(C_{1}\right)$ is computed and compared with the current ones $\left(C_{0}\right)$. A move to a new solution is made either the new solution has better value or the value of SA probability function (Eq. (9)) is higher than a randomly generated number between 0 and 1 [22]:

$$
P_{r}=\exp \left(-\frac{\Delta C}{T_{k}}\right)
$$

Where, temperature parameter is shown by $T_{k}$, which acts as the temperature in the physical annealing process does [21]. Eq. (10), is used as a temperature reduction rate to cool down the pre-determined temperature at each iteration.

$$
\mathrm{T}_{\mathrm{k}+1}=\alpha \times \mathrm{T}_{\mathrm{k}} \quad \mathrm{k}=0,1, \ldots \text { and } \quad 0.9 \leq \alpha<1
$$

Where, the current and former temperatures are shown by $T_{k+1}$ and $T_{k}$ respectively. The cooling rate also presented by parameter a. Consequently, at the first iterations of SA due to higher temperature, most of the not improving (or even worsening) moves may be accepted. Nonetheless, as the algorithm proceeds and temperature is reduced only improving moves are likely to be accepted. This strategy could help the algorithm avoid being trapped in local minimum and jump out of it. After a specific number of iterations, a number of iterations in which no development is detected, and a pre-determined run time, the algorithm may be dismissed.

\subsection{Particle swarm optimization (PSO) algorithm}

PSO is a heuristic algorithm proposed by Kennedy and Eberhart [24]. It begins with a population of random solutions which is updated and searched for optimum ones. The current optimum particles are followed by the random solutions (known as particles) through the problem space. The problem space is connected with the best obtained solution and its corresponding location shown by "pBest" and "gBest" respectively. Each particle keeps track of the "pBest" and "gBest" in the problem space by changing its velocity towards them. The following Equations (11 and 12) used updating the particles [25-27].

$$
\begin{aligned}
& V_{i+1}=w \times V_{i}+\left(C_{1} \times r_{i} \times\left(\text { pBest }_{i}-X_{i}\right)\right)+\left(C_{2} \times r_{i} \times\left(g B e s t_{i}-X_{i}\right)\right)(11) \\
& X_{i+1}=X_{i}+V_{i+1}(12)
\end{aligned}
$$


Where, $\left(V_{i+1}\right)$ for each particle has been determined based on its previous velocity $\left(V_{i}\right)$, global best solution (pBest) and location (gBest). Eq. (9) has been used for updating the particle's position $\left(X_{i}\right)$ [27]. The terms " $r_{1}$ " and " $r_{2}$ " are two random numbers generated independently in the range of $[0,1]$. There are acceleration constants (" $c_{1}$ " and " $c_{2}$ ") using which pull each particle (solution) towards "pBest" and "gBest" positions. Inertia weight " $w$ ", acts as an important parameter in PSO algorithm convergence behavior. In order to explore the answer space globally, the large amount of " $w$ " required, while the small amounts explore nearby regions of the space [28].

Based on the literature survey, the architecture (number of hidden layers and nods in hidden layers) of BPNN in most studies has been determined using trial and error. Whereas, in this study PSO algorithm has been employed to determine the PBNN architecture. Furthermore, the optimization of the proposed BPNN models have been carried out using PSO algorithm. Moreover, SA algorithm has been used to confirm the performance of PSO algorithm (avoiding getting trapped in the local optima).

The performance of each evolutionary algorithm is affected by its own distinctive adjusting parameters. The details of the PSO performance are well documented in Refs [23-27].

The adjusting parameters used for controlling the SA and PSO algorithms are carried out as the following.

PSO variables: Population: 50; Learning factor $\mathrm{c}_{1}$ and $\mathrm{c}_{2}: 2$; Number of iteration performed: 30 .

$S A$ variables. Temperature reduction rate: 0.91; Processing time: 30; seconds Initial temperature: 700.

\section{Results And Discussion}

Different weights $\left(W_{1}\right.$ and $\left.W_{2}\right)$ may have been considered for A-GTAW process responses (DOP and WBW) based on the importance considered. In this study the value of 0.5 has been considered for $W_{1}$ and $W_{2}$ for DOP and WBW. In this study optimization procedure has been used for two conditions. In the first condition the demotion of weld bead geometry has not been restricted. In the second condition the dimensional restriction has been imposed to the optimization procedure. In the second condition, the maximum value for DOP has been considered $5 \mathrm{~mm}$. At the same token desired AR ([1.0-1.4]) has been taken into account as the second limitation. Figure 14, illustrates the cross section of weldment for optimization of the second condition. Based on the nature of the PSO algorithm, its convergence is faster than SA algorithm. Furthermore, as the PSO drawback is falling into optimum traps, its performance could be better to be checked by another algorithm. In this paper, the performance of PSO algorithm has been checked by SA algorithm. The convergence of PSO and SA algorithms has been shown by Fig. 15 . Tables 5 and 6, represents the results of PSO and SA optimization for the both mentioned conditions. Based on the results, PSO and SA could accurately optimize the process responses (with less than 7\% error). 
Table 5

Optimal A-TIG welding process variables and coressponding process measures for CCD matrix

\begin{tabular}{|c|c|c|c|c|c|c|c|}
\hline \multirow[t]{2}{*}{ Output } & \multirow[t]{2}{*}{ Algorithm } & \multicolumn{3}{|c|}{ Process variables } & \multirow[t]{2}{*}{ Predicted } & \multirow[t]{2}{*}{ Experimental } & \multirow[t]{2}{*}{ Error (\%) } \\
\hline & & $\mathbf{F}$ & $S$ & C & & & \\
\hline \multicolumn{2}{|c|}{$W_{\text {DOP }}=0.50$ and $W_{W B W}=0.50$} & \multicolumn{6}{|c|}{ Considering weld bead geometry restriction } \\
\hline DOP & SA & 60 & 190 & 129 & 4.96 & 5.11 & 3.0 \\
\hline DOP & PSO & 71 & 190 & 128 & 4.95 & 5.07 & 2.4 \\
\hline WBW & SA & 60 & 190 & 129 & 5.70 & 5.56 & 2.7 \\
\hline WBW & PSO & 71 & 190 & 128 & 5.68 & 5.55 & 2.1 \\
\hline AR & SA & 60 & 190 & 129 & 1.14 & 1.08 & 5.2 \\
\hline AR & PSO & 71 & 190 & 128 & 1.14 & 1.09 & 5.1 \\
\hline
\end{tabular}

Table 6

Optimal A-GTAW welding process variables and coressponding process measures for BBD matrix

\begin{tabular}{|c|c|c|c|c|c|c|c|}
\hline \multirow[t]{2}{*}{ Output } & \multirow[t]{2}{*}{ Algorithm } & \multicolumn{3}{|c|}{ Process variables } & \multirow[t]{2}{*}{ Predicted } & \multirow[t]{2}{*}{ Experimental } & \multirow[t]{2}{*}{ Error (\%) } \\
\hline & & $\mathbf{F}$ & 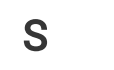 & $\mathrm{C}$ & & & \\
\hline \multicolumn{8}{|c|}{$W_{D O P}=0.50$ and $W_{W B W}=0.50$} \\
\hline DOP & SA & 74 & 133 & 100 & 4.92 & 4.62 & 6.0 \\
\hline DOP & PSO & 75 & 134 & 100 & 4.94 & 4.68 & 5.5 \\
\hline WBW & SA & 74 & 133 & 100 & 5.61 & 5.36 & 4.3 \\
\hline WBW & PSO & 75 & 134 & 100 & 5.62 & 5.40 & 4.0 \\
\hline ASR & SA & 74 & 133 & 100 & 1.14 & 1.16 & 1.8 \\
\hline ASR & PSO & 75 & 134 & 100 & 1.13 & 1.15 & 1.8 \\
\hline
\end{tabular}

\section{Conclusion}

An important factor which affects the weldments' quality in different welding processes is the proper selection of process variables levels. The modeling and optimization of A-TIG welding process for AISI316L austenite stainless steel parts considering both the process variables and percentage of activating fluxes combination has been addressed throughout this study. First, CCD based on RSM has been employed to determine the experimental design matrix required for data gathering, modeling and optimization purposes. Next, DOP and WBW values have been measured using MIP software. Based on the results of WBW and DOP, AR values have been computed. Then, BPNN has been employed to 
establish the relations between process input variables (welding speed, current and percentage of activating fluxes combination) and output responses (DOP, WBW and AR). Moreover, in order to determine the proper BPNN architecture, PSO algorithm has been used. Then, PSO algorithm has been used again to optimize the proposed proper BPNN model in such a way that DOP increased and WBW decreased simultaneously and achieved the desired AR. Furthermore, the PSO algorithm performance has been checked using SA algorithm. Using the proposed hybrid BPNN-PSO approach either process input variables have been optimized (190 mm/sec for welding speed and $128 \mathrm{Amp}$ for welding current) and the optimum formula $\left(71 \% \mathrm{SiO}_{2}\right.$ and $\left.29 \% \mathrm{TiO}_{2}\right)$ for activating fluxes combination has been determined in order to achieve the desired process output measures (maximum DOP, minimum WBW and desired AR). The result of proposed optimization procedure showed that the proposed method can precisely simulate and optimize (with less than 7\% error) the A-TIG welding process.

\section{Nomenclature}




\begin{tabular}{|c|c|}
\hline Artificial neural network & ANN \\
\hline Particle swarm optimization & PSO \\
\hline Activated gas tangent arc welding & A-GTAW \\
\hline Gas tangent arc welding & GTAW \\
\hline Design of experiments & DOE \\
\hline Box-behnken design & BBD \\
\hline Central composite design & CCD \\
\hline Weld bead width & WBW \\
\hline Welding current & I \\
\hline Welding speed & S \\
\hline Back propagation neural network & BPNN \\
\hline Microstructural image processing & MIP \\
\hline Multi-layer perceptron & MLP \\
\hline Mean squared error & MSE \\
\hline New solution & $\mathrm{C}_{1}$ \\
\hline Current solution & $\mathrm{C}_{0}$ \\
\hline Current temperatures & $\mathrm{T}_{\mathrm{k}+1}$ \\
\hline Former temperatures & $\mathrm{T}_{\mathrm{k}}$ \\
\hline Cooling rate & $a$ \\
\hline Velocity & $\mathrm{V}_{\mathrm{j}}$ \\
\hline Position & $X_{j}$ \\
\hline Random numbers & $r_{1}$ and $r_{2}$ \\
\hline Acceleration parameters & $\mathrm{c}_{1}$ and $\mathrm{c}_{2}$ \\
\hline Inertia weight & $\mathrm{Y}$ \\
\hline Best position of particle & $\mathrm{p}_{\mathrm{j}}$ \\
\hline Best position of group & $\mathrm{pg}_{\mathrm{g}}$ \\
\hline Particle & $j^{\text {th }}$ \\
\hline
\end{tabular}




\begin{tabular}{ll} 
Current velocity & $\mathrm{V}_{\mathrm{j}+1}$ \\
\hline Former velocity & $\mathrm{V}_{\mathrm{j}}$ \\
\hline Particle's position & $\mathrm{X}_{\mathrm{i}}$ \\
\hline Global best location & $\mathrm{gBest}$ \\
\hline Current best location & $\mathrm{pBest}$ \\
\hline Inertia weight & $\mathrm{w}$
\end{tabular}

\section{Declarations}

\section{Acknowledgments}

We are thankful to the editor and reviewer of this journal for suggesting the valuable improvements and allowing appropriate time for updating the manuscript.

\section{Conflicts of interest}

The authors whose names are listed immediately below certify that they have NO affiliations with or involvement in any organization or entity with any financial interest (such as honoraria; educational grants; participation in speakers' bureaus; membership, employment, consultancies, stock ownership, or other equity interest; and expert testimony or patent-licensing arrangements), or non-financial interest (such as personal or professional relationships, affiliations, knowledge or beliefs) in the subject matter or materials discussed in this manuscript.

\section{Funding}

Not applicable' for this section

\section{Availability of data and material}

The data and material could be available if is required

\section{Code availability}

The Code could be available if is required

\section{Ethics approval}

The manuscript will not be submitted elsewhere until the editorial process is completed.

\section{Consent for publication}


The Authors grant the Publisher the sole and exclusive license of the full copyright in the Contribution, which license the Publisher hereby accepts. Consequently, the Publisher shall have the exclusive right throughout the world to publish and sell the Contribution in all languages, in whole or in part, including, without limitation, any abridgement and substantial part thereof, in book form and in any other form including, without limitation, mechanical, digital, electronic and visual reproduction, electronic storage and retrieval systems, including internet and intranet delivery and all other forms of electronic publication now known or hereinafter invented.

\section{References}

1. Vidyarthy RS, Kulkarni A, Dwivedi DK, Study of microstructure and mechanical property relationships of A-TIG welded P91-316L dissimilar steel joint, Materials Science \& Engineering A, 2017; 695: 249257.

2. Ramkumar KD, Varma V, Prasad M, Rajan ND, Effect of activated flux on penetration depth, microstructure and mechanical properties of Ti-6Al-4V TIG welds. Journal of Materials Processing Tech, 2018; 261: 233-241.

3. Zou Y, Ueji R, Fujii H, Mechanical properties of advanced active-TIG welded duplex stainless steel and ferrite steel, Materials Science and Engineering A, 2015; 620: 140-148.

4. Kulkarni A, Dwivedi DK, Vasudevan M, Dissimilar metal welding of P91 steel-AISI 316L SS with Incoloy 800 and Inconel 600 interlayers by using activated TIG welding process and its effect on the microstructure and mechanical properties, Journal of Materials Processing Technology, 2019; 274: 116-128.

5. Vidyarthy RS, Dwivedi DK, Microstructural and mechanical properties assessment of the P91 A-TIG weld joints, Journal of Manufacturing Processes, 2018; 31: 523-535.

6. Dhandha KH, Badheka VJ. Effect of activating fluxes on weld bead morphology of P91 steel beadon-plate welds by flux assisted tungsten inert gas welding process. Mater Manuf Processes 2015; 17:48-57.

7. Pamnani R, Vasudevan M, Vasantharaja P, Jayakumar T, “Optimization of A-GTAW welding parameters for naval steel (DMR 249 A) by design of experiments approach", Proc IMechE Part L: J Materials Design and Applications, 2015; 34: 1-12.

8. Arivazhagan B, Vasudevan M. Studies on A-TIG welding of $2.25 \mathrm{Cr}-1 \mathrm{Mo}$ (P22) steel. Mater Manuf Processes 2015; 18:55-9.

9. Arivazhagan B, Vasudevan M. A comparative study on the effect of GTAW processes on the microstructure and mechanical properties of P91 steel weldjoints. Mater Manuf Processes 2014; 16:305-11.

10. Ahmadi E, Ebrahimi AR, "Welding of 316L Austenitic Stainless Steel with Activated Tungsten Inert Gas Process", JMEPEG, 2015; 24: 1065-1071. 
11. Kurtulmus $M$, "Effects of welding parameters on penetration depth in mild steel A-TIG welding", Scientia Iranica B, 2019; 26: 1400-1404.

12. Kumar, V. B. Lucas, D. Howse, G. Melton, S. Raghunathan, L. Vilarinho, Investigation of the A-TIG Mechanism and the Productivity Benefits in TIG Welding. In JOM-15, Fifteenth International Conference on the Joining of Materials, December 2009.

13. G. Venkatesan, J. George, M. Sowmyasri, V. Muthupandi, Effect of Ternary Fluxes on Depth of Penetration in A-TIG Welding of AISI 409 Ferritic Stainless Steel, Procedia Materials Science, 5(2) (2014) 2402-2410.

14. T.S. Chern, K.H. Tseng, H.L. Tsai, Study of the characteristics of duplex stainless steel activated tungsten inert gas welds, Materials \& Design, 32 (1) (2011) 255-263.

15. Tathgir, S. Bhattacharya, A. Activated-TIG welding of different steels: influence of various flux and shielding gas, Materials and Manufacturing Processes, 31(3) (2015) 335-342.

16. Víctor Martínez-Martínez, Francisco Javier Gomez-Gil, Jaime Gomez-Gil, Ruben Ruiz-Gonzalez, An Artificial Neural Network based expert system fitted with Genetic Algorithms for detecting the status of several rotary components in agro-industrial machines using a single vibration signal, Expert Systems with Applications, 42 (2015) 6433-6441.

17. Markopoulos, A. P. Manolakos, D.E. and Vaxevanidis, N.M. "Artificial neural network models for the prediction of surface roughness in electrical discharge machining", Journal of Intelligence Manufacturing, 12(2), pp. 283-292 (2008).

18. Sahin H, Topal B, "Impact of information technology on business performance: Integrated structural equation modelling and artificial neural network approach", Scientia Iranica B, 2018; 25: 1272-1280.

19. Kurtulmus $M$, and Kiraz A. "Artificial neural network modelling for polyethylene FSSW parameters", Scientia Iranica B, 2018; 25: 1266-1271.

20. Neville. Gregory, why do welds crack? TWI Bull March/April 1991:1-8.

21. Pamnani R, Vasudevan $M$, Vasantharaja P, Jayakumar T. "Optimization of A-GTAW welding parameters for naval steel (DMR 249 A) by design of experiments approach", Proc IMechE Part L: J Materials: Design and Applications, 2015, pp. 1-12.

22. Jahromi MHMA, Tavakkoli-Moghaddam R, Makui A, Shamsi A (2012) Solving an one-dimensional cutting stock problem by simulated annealing and tabu search. Journal of Industrial Engineering International 8:1-8.

23. Ayubi Rad MA, Ayubi Rad MS, "Comparison of artificial neural network and coupled simulated annealing based least square support vector regression models for prediction of compressive strength of high-performance concrete", Scientia Iranica A, 2017; 24: 487-496.

24. Lee KH, Kim KW (2015) Performance comparison of particle swarm optimization and genetic algorithm for inverse surface radiation problem. International Journal of Heat and Mass Transfer 88: 330-337

25. Zhi, K. Jia, W. Zhang, G. and Wang, L. "Normal parameter reduction in soft set based particle swarm optimization algorithm", applied mathematical modeling, 39(3), pp. 4808-4820 (2015). 
26. Azadi Moghaddam M, Kolahan F, "Using combined artificial neural network and particle swarm optimization algorithm for modeling and optimization of electrical discharge machining process", Scientia Iranica $B, 2018$; in press.

27. Hasheminejad MM, Sohankar N, Hajiannia A, "Predicting the Collapsibility Potential of Unsaturated Soils Using Adaptive Neural Fuzzy Inference System and Particle Swarm Optimization", Scientia Iranica A, 2018; 25: 2980-2996.

28. Azadi Moghaddam M, Golmezergi R, Kolahan F, "Multi-variable measurements and optimization of GMAW parameters for API-X42 steel alloy using a hybrid BPNN-PSO approach", Measurement, 2016; 92: $279-287$.

\section{Figures}
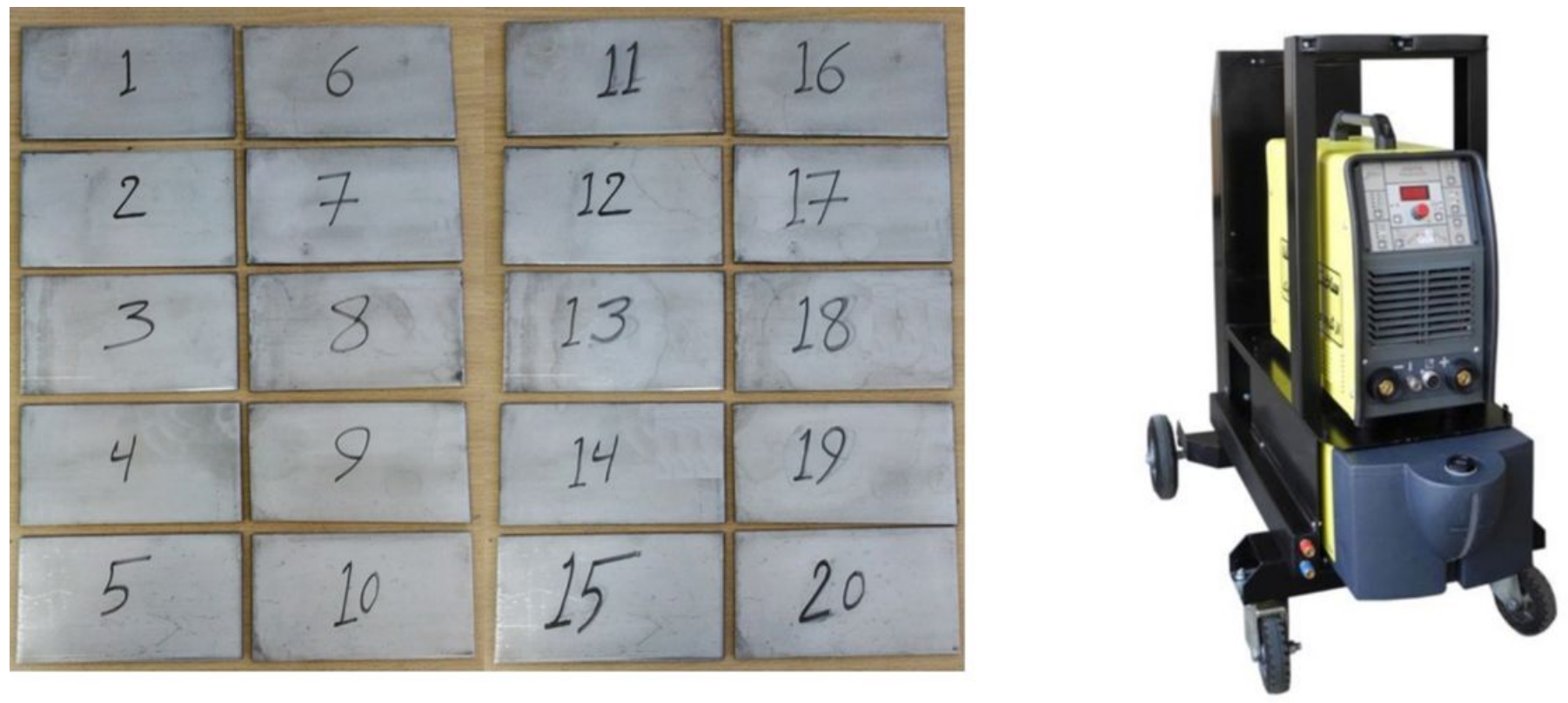

\section{Figure 1}

Workpieces and welding machine used 


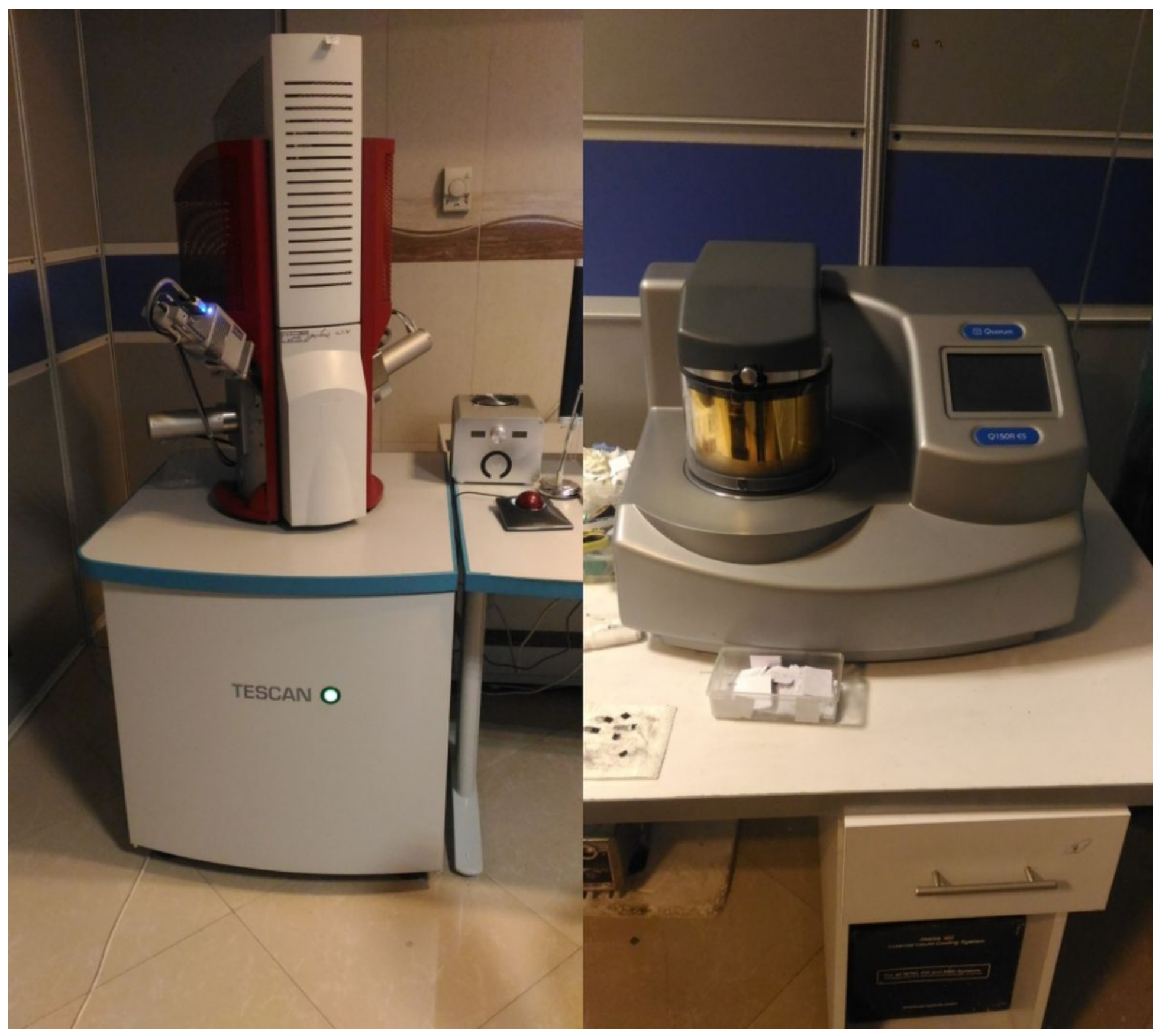

Figure 2

FESEM test equipment used 


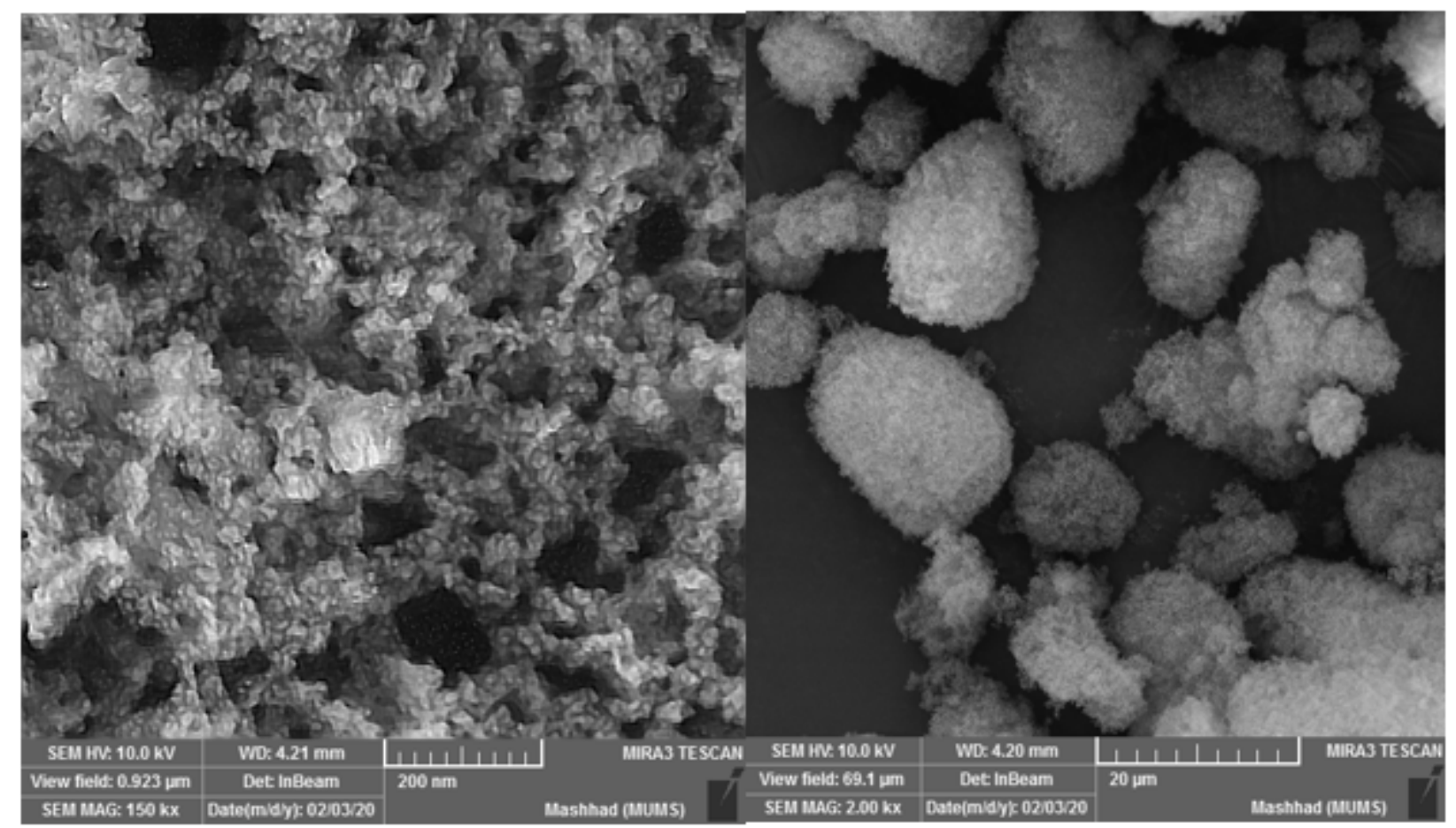

Figure 3

Nano activating flux (SiO2) and results of FESEM tests
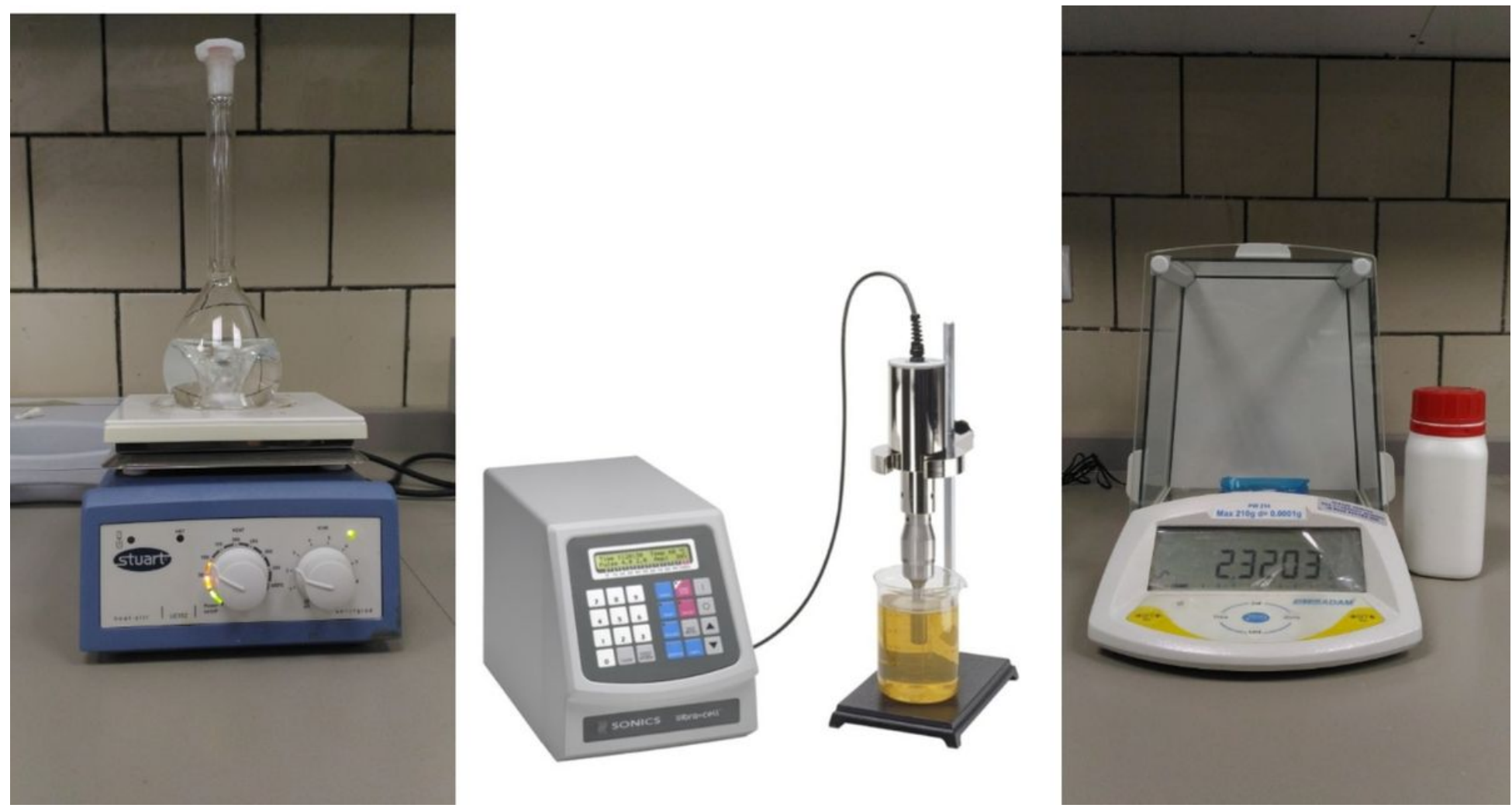

Figure 4

Magnetic and ultrasonic mixers and electronic balance used 


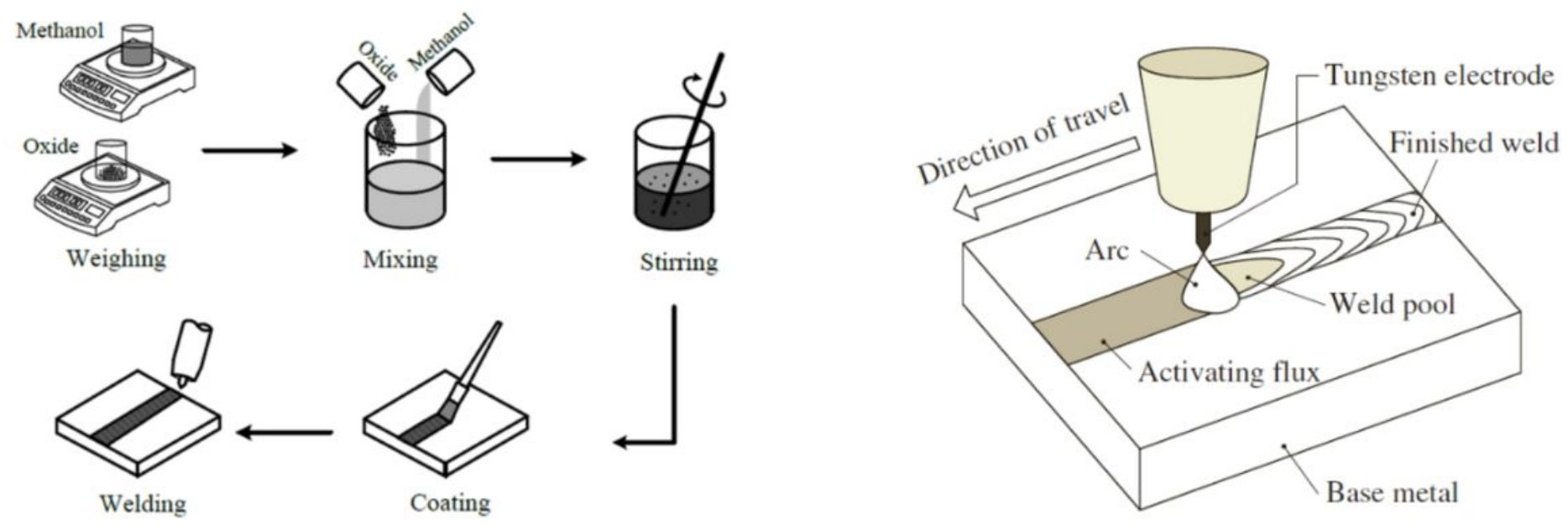

Figure 5

Schematic illustration of preparation of activating paste-like flux and A-GTAW process

FFD

Full Factorial Design

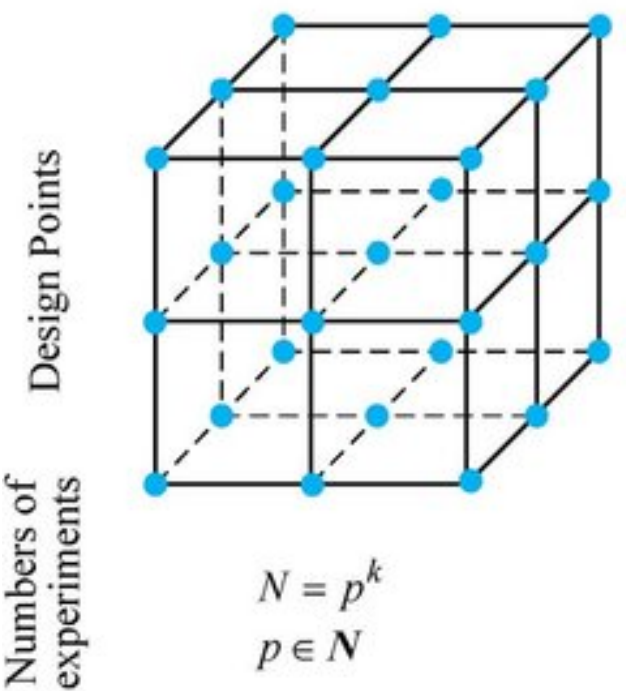

意

- All levels and possible factor interactions can be evaluated

- Computation intense
CCD

Central Composite Design

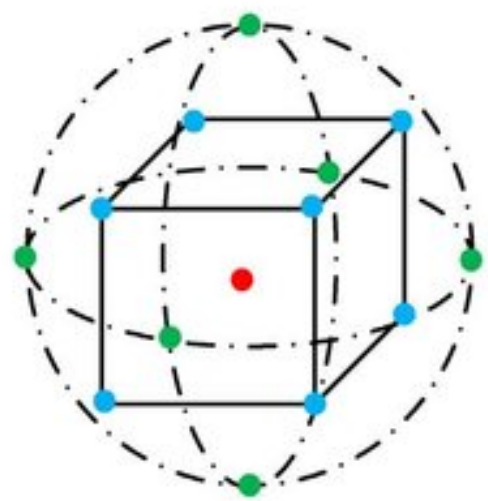

$$
\begin{gathered}
N=2^{k}+2 k+1 \\
p=5
\end{gathered}
$$

- Factorial points are at the surface of $k$ dimensional sphere

- Significant design points
BBD

Box-Behnken Design

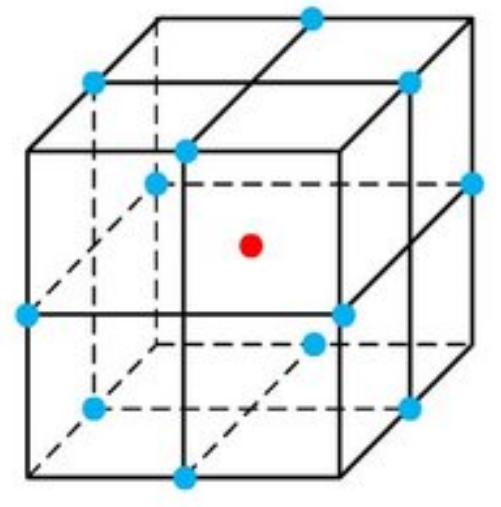

Tabulated design

$$
p=3
$$

- Corner points can be estimated

- Only for second degree polynomial

Figure 6

Schematic illustration of full factorial; box-behnken and central composite designs 


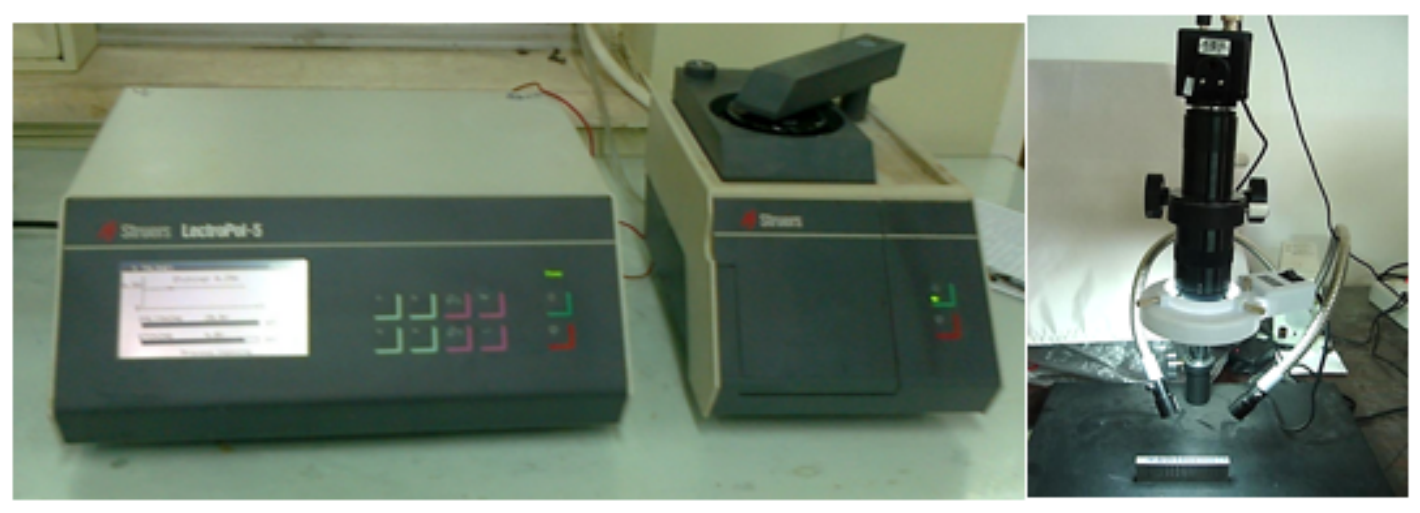

Figure 7

Optical microscope and electro polish machine used 

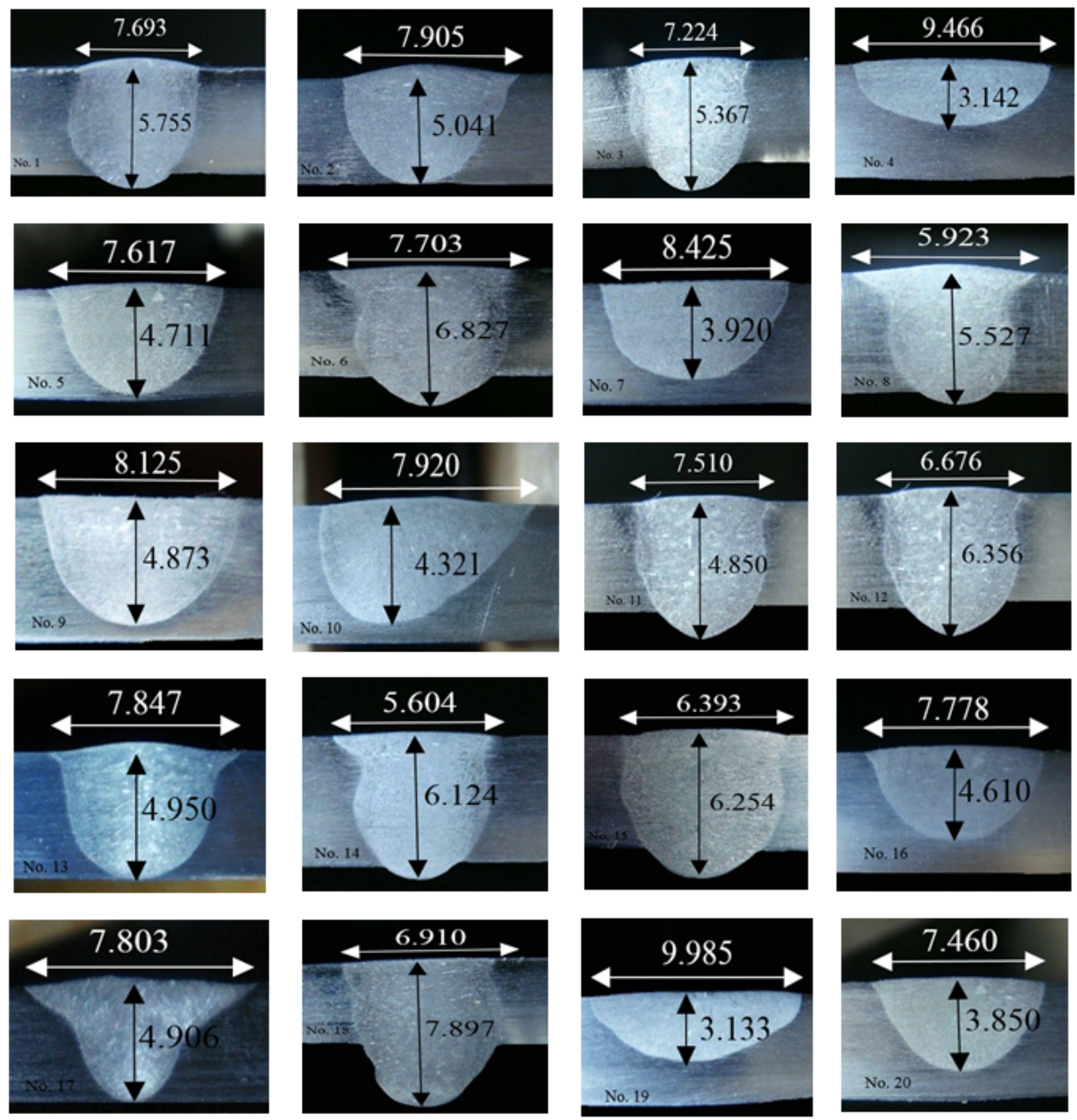

Figure 8

A-TIG weld cross-sectional profile for CCD matrix 

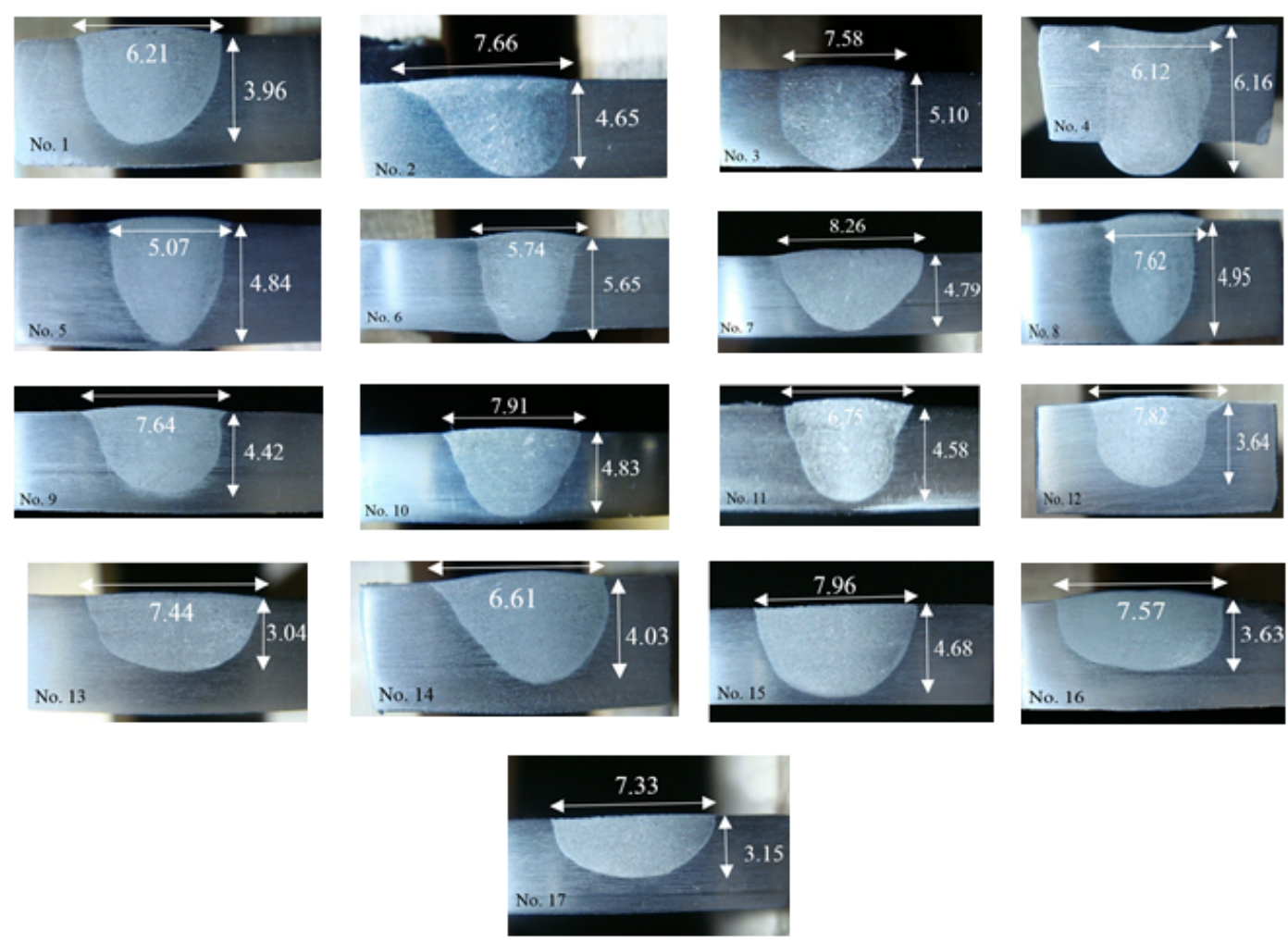

Input Layer Hidden Layers $\quad$ Output Layer
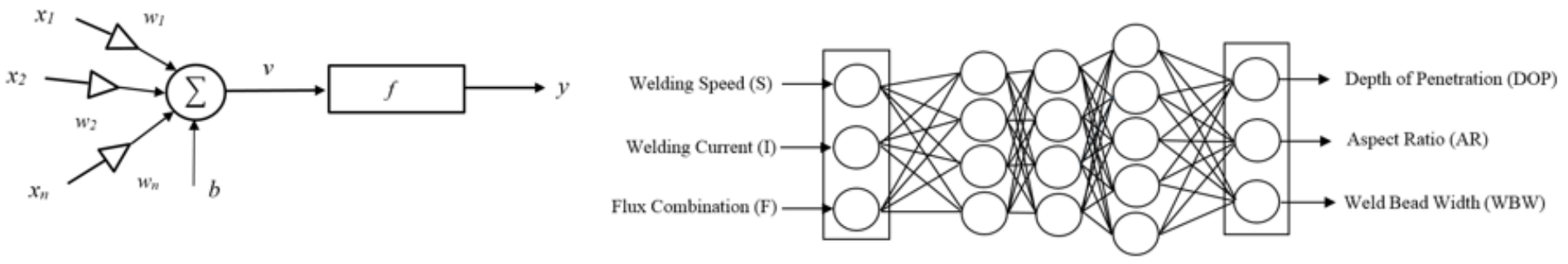

(a)

(b)

Figure 9

A-GTAW weld cross-sectional profile for BBD matrix (a) Example of perceptron and (b) architecture of proposed ANN model 


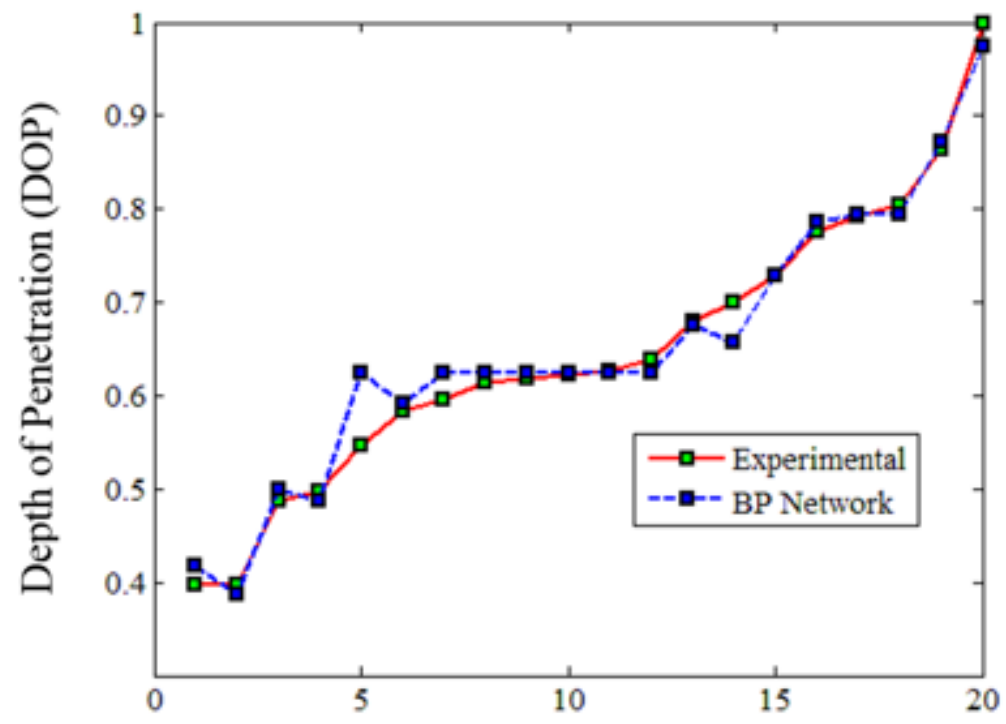

Number of Experiments

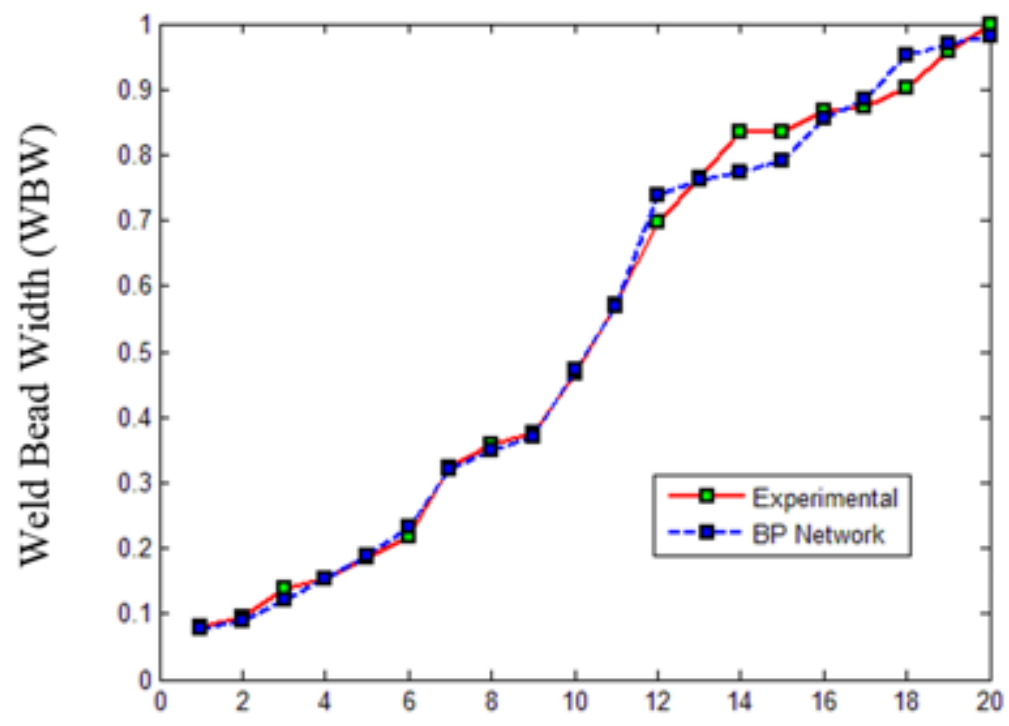

Figure 10

Comparison of process responses and proposed BPNN model predictions based on CCD matrix 


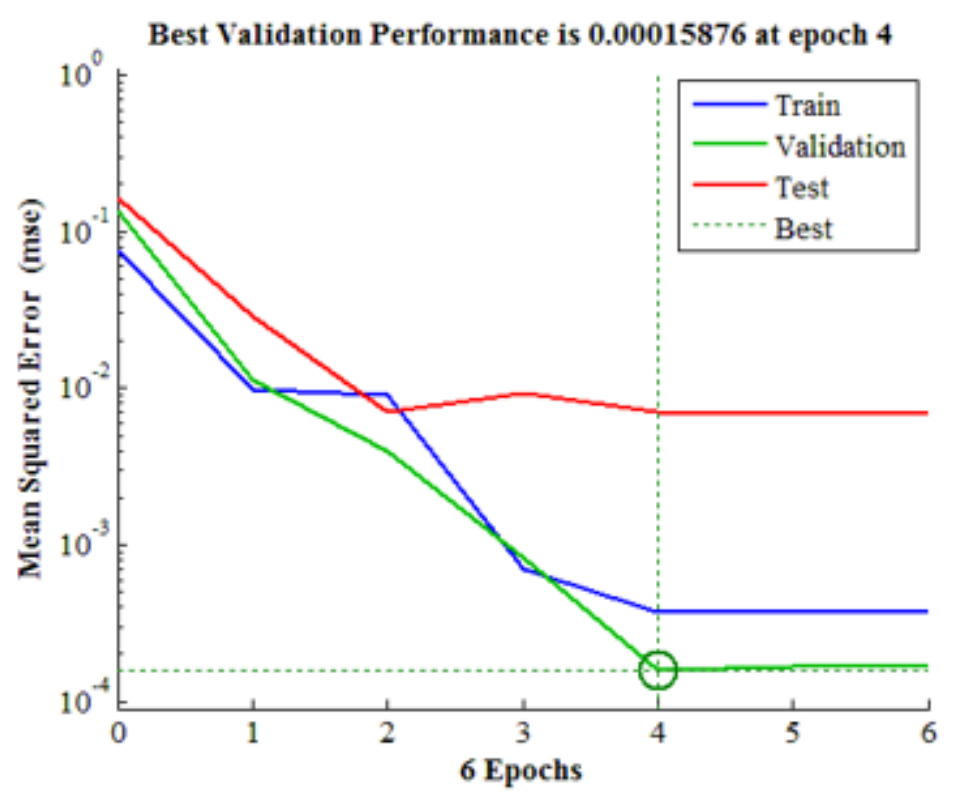

Figure 11

Variation of mean squared error (MSE) for CCD matrix 
Training: $\mathrm{R}=0.98065$

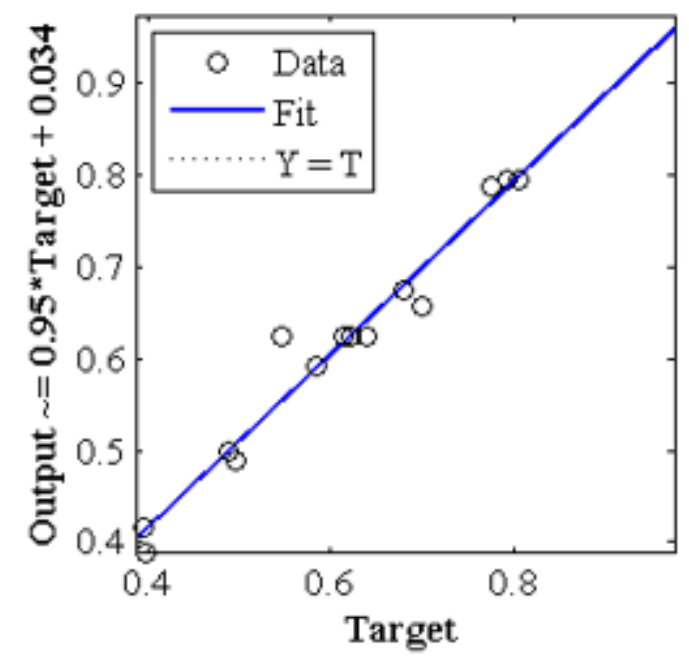

Test: $\mathrm{R}=0.99814$

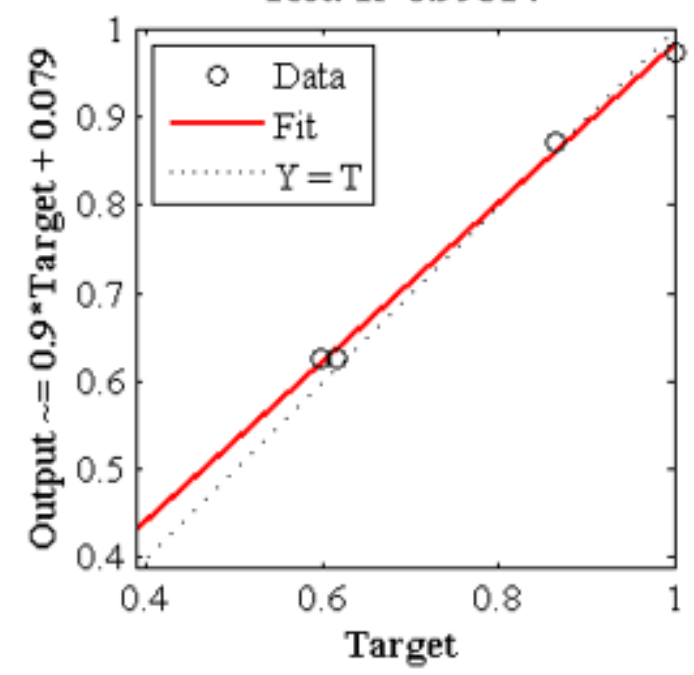

Validation: $\mathrm{R}=1$

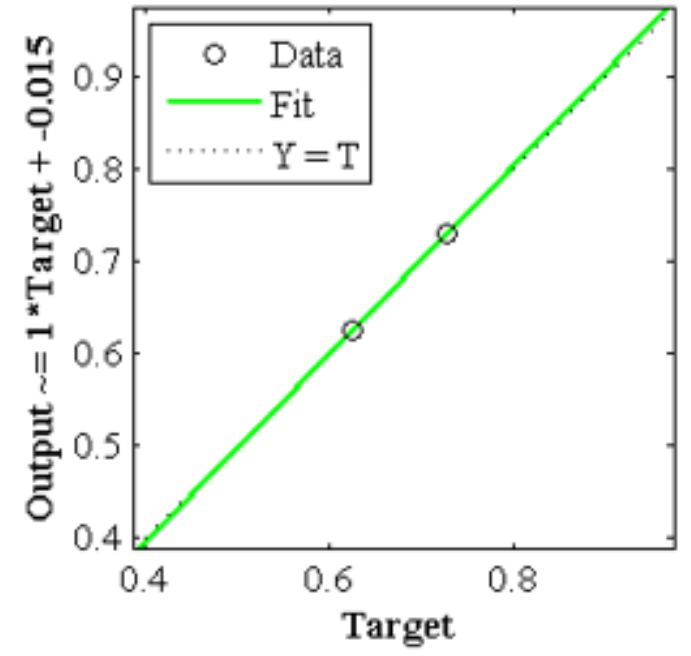

All: $\mathrm{R}=0.9883$

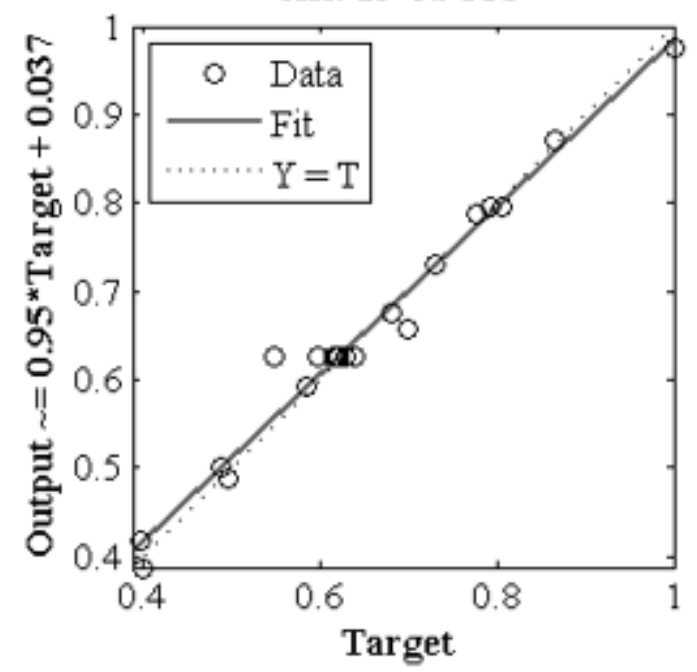

Figure 12

Performance of the proposed BPNN model in training, validation and test stages for CCD matrix

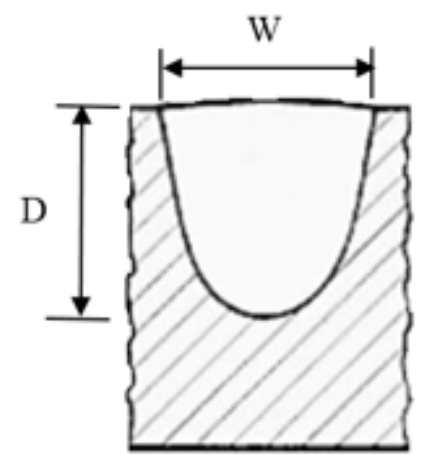

$\mathrm{W} / \mathrm{D}=1$

Sound Weld

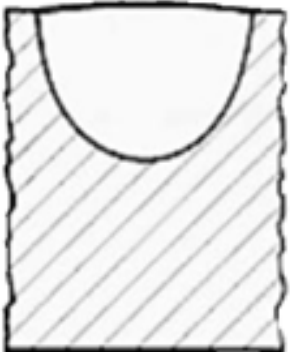

$\mathrm{W} / \mathrm{D}=1.4$

Sound Weld

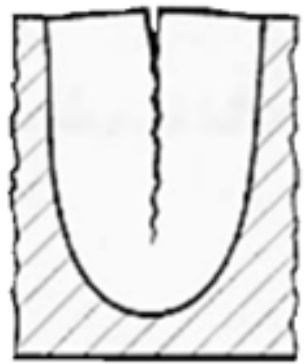

$\mathrm{W} / \mathrm{D}=0.7$

Weld Tends to Crack

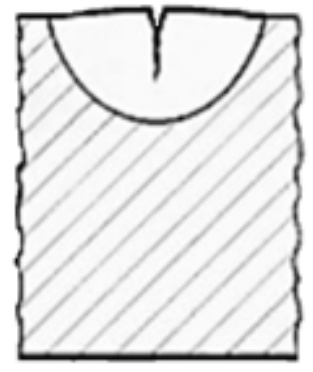

$\mathrm{W} / \mathrm{D}=0.7$

Weld Tends to Crack

Figure 13 
Effect of aspet ratio values on tendency of occuring solidification cracking
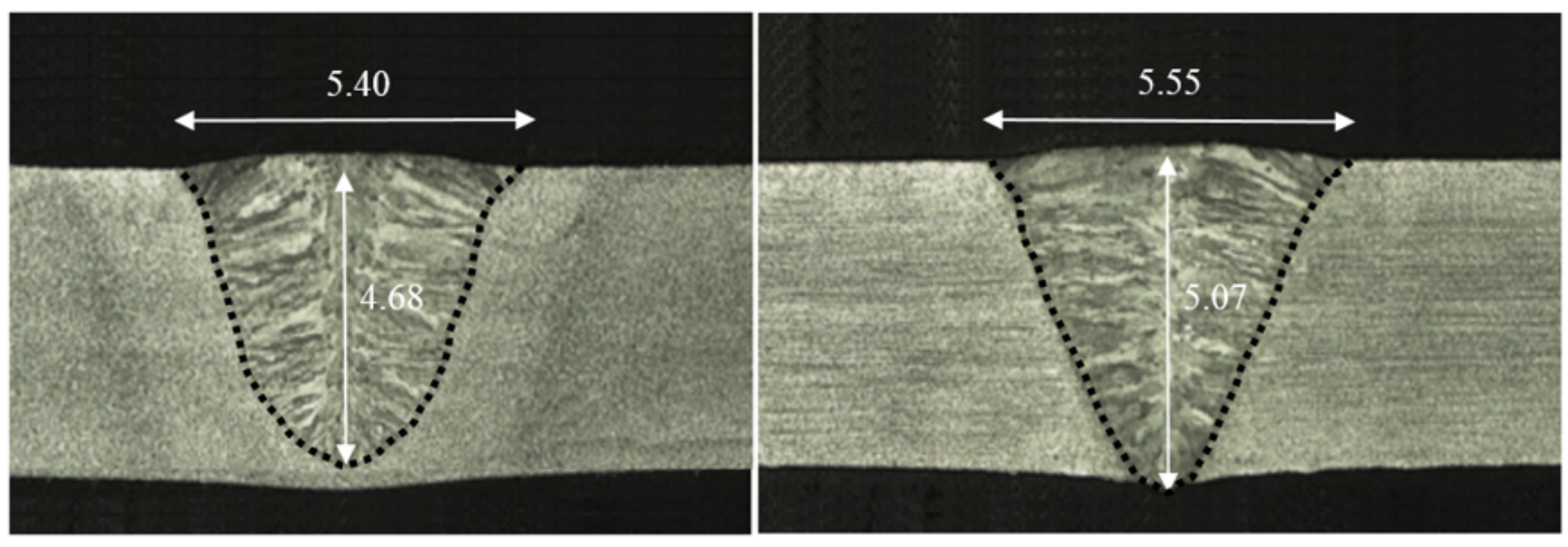

Figure 14

Evaluation of DOP and WBW for the optimized condition based on BBD and CCD matrix

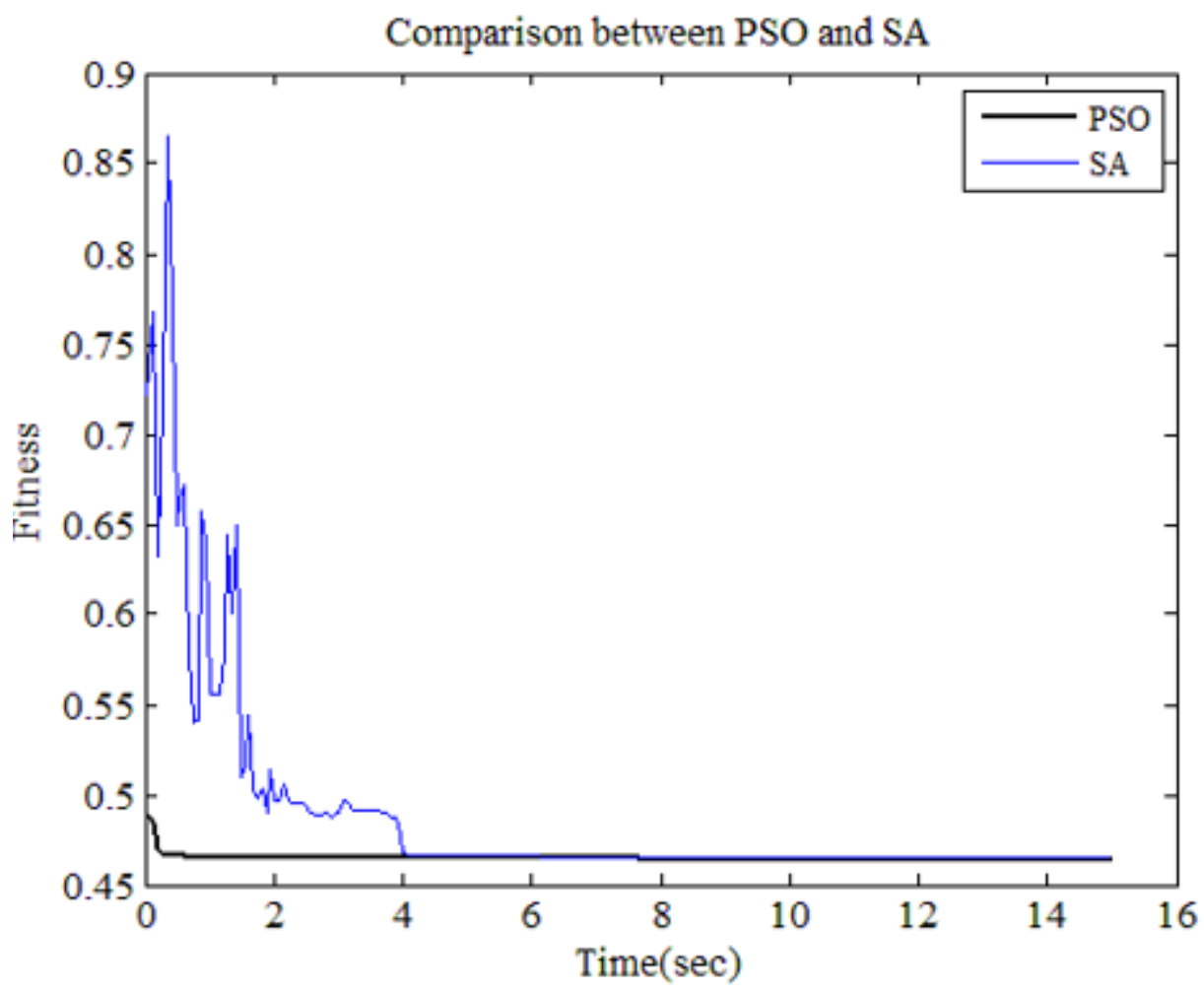

Figure 15

Convergence of heuristic (PSO and SA) algorithms 